\title{
Does illness experience influence the recall of medical information?
}

\author{
B Krishnan, C Glazebrook, A Smyth
}

\begin{abstract}
Recall of a storyboard description of an unfamiliar illness was assessed in 66 healthy children and 40 children with chronic illness (cystic fibrosis or asthma). A significant interaction between verbal intelligence quotient and illness experience $(p<0.001)$ suggested that more able sick children may be resistant to learning new medical information. (Arch Dis Child 1998;79:514-515)
\end{abstract}

Keywords: chronic illness; memory

There is increasing concern that children with chronic illness should be fully informed about their illness to reduce anxiety, increase adherence to medical regimens, and involve them in treatment decisions. ${ }^{1}$ Age, intelligence, and Piagetian stage of development all influence children's ability to understand medical information. ${ }^{23}$ However, evidence suggests that even experienced clinicians find it difficult to judge children's level of cognitive development. ${ }^{4}$ Furthermore, most paediatricians assume that children with a chronic illness are better able to understand and retain information than their less experienced peers.

Analogous explanations are commonly used by clinicians to inform children about their illness and treatment. Janovic et al, for example, used a garden analogy with weeds representing malignant cells to communicate a diagnosis of leukaemia to young sufferers. ${ }^{5}$ The effective-

Accepted 6 July 1998

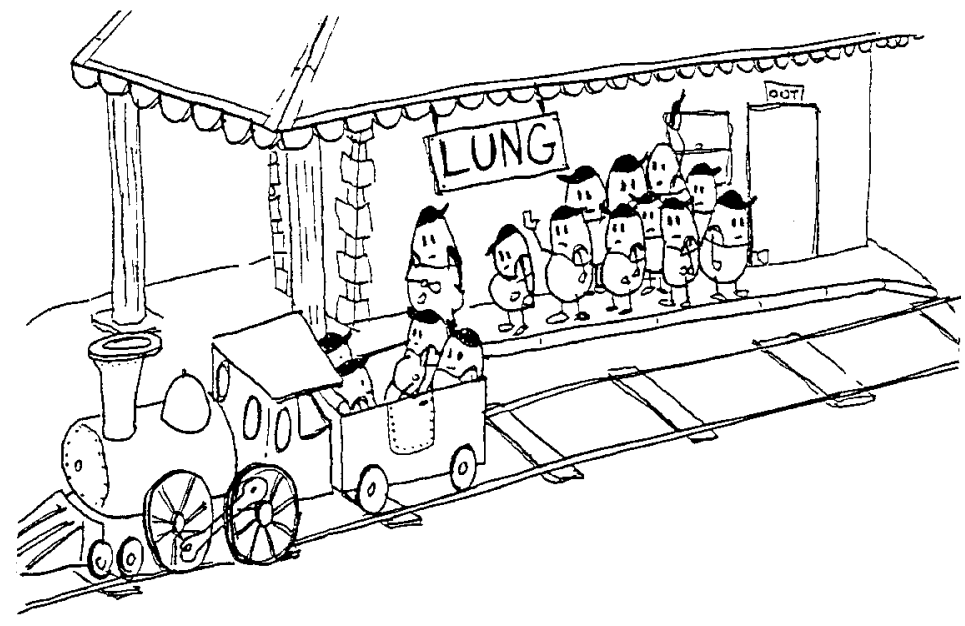

"If people do not get enought of the right foods there is not enough iron to make all the seats on

the train we need. So the train cannot carry enough oxygen workers"

Figure 1 Storyboard explanation of iron deficiency in anaemia. ness of such techniques with medically experienced paediatric patients has not been investigated.

\section{Methods}

Forty children with a chronic illness (15 with cystic fibrosis and 25 with chronic asthma) were recruited from specialist paediatric outpatient clinics. An age stratified, random sample of 66 children with no chronic health problems was recruited from one primary school, in a socially mixed catchment area. Demographic information was obtained from parents in the clinic, or by post for the comparison group, and parents were asked to rate their child's experience of illness on a five point scale.

In the testing session, each child was given an attractive storyboard explanation of iron deficiency anaemia. A train analogy was used to explain the function of the blood in carrying oxygen "workers" from the lung "station" to the rest of the body. The workers need seats on the train which are made by iron from food. Not enough iron means not enough seats so not enough oxygen workers travelling on the train (fig 1).

An assessment was made of verbal intelligence quotient (IQ) (British Picture Vocabulary Scales-short form) and ability to conserve mass and number. Finally, the child was asked four open ended questions about the nature, cause, treatment, and symptoms of anaemia. Each response was scored for level of knowledge on a scale from 0 to 4 , giving a maximum total score of 16 . A random sample of the responses was rescored by a "blind", independent rater and inter-rater reliability was found to be high (weighted $\kappa=0.981$, $\mathrm{p}<0.0001$ ).

Analysis of variance was done with illness experience (healthy $v$ chronic illness), verbal IQ (above or equal to the median $v$ below the median), and sex as the independent factors and total anaemia knowledge score (log transformed) as the dependent variable. Age of child was entered as a covariate.

\section{Results}

The mean (SD) age of children in the study group was 7.6 (2.26) years and in the comparison group 8.0 (2.05) years. The study group contained $24(60 \%)$ boys and the comparison group $32(49 \%)$. The study and comparison groups did not differ significantly in age, sex, social class, verbal IQ or conversation ability. Children in the study group were rated as having greater experience of illness than children in the comparison group $(z=5.95$, $\mathrm{p}<0.0001)$ and they had spent more days in hospital $(\mathrm{z}=3.9, \mathrm{p}<0.0001)$. 
Table 1 Total anaemia knowledge scores (log transformed and adjusted for age) in healthy children and children with a chronic illness

\begin{tabular}{llll}
\hline \multirow{2}{*}{ Group } & \multicolumn{2}{c}{ Mean $(S D)$ anaemia knowledge } & \multicolumn{2}{c}{$\begin{array}{l}\text { Mean }(S E) \\
\text { difference }\end{array}$} \\
\cline { 2 - 3 } & $\begin{array}{l}\text { Healthy } \\
\text { group }\end{array}$ & $\begin{array}{l}\text { Chronic illness } \\
\text { group }\end{array}$ & $0.046(0.086)$ \\
Lower IQ & $\begin{array}{l}0.62(0.31) \\
(\mathrm{n}=27)\end{array}$ & $\begin{array}{l}0.57(0.3) \\
(\mathrm{n}=24)\end{array}$ & $0.423(0.097)$ \\
Higher IQ & $\begin{array}{l}0.79(0.37) \\
(\mathrm{n}=39)\end{array}$ & $\begin{array}{l}0.37(0.38) \\
(\mathrm{n}=16)^{\star}\end{array}$ & \\
\hline
\end{tabular}

${ }^{\star} \mathrm{p}<0.001$

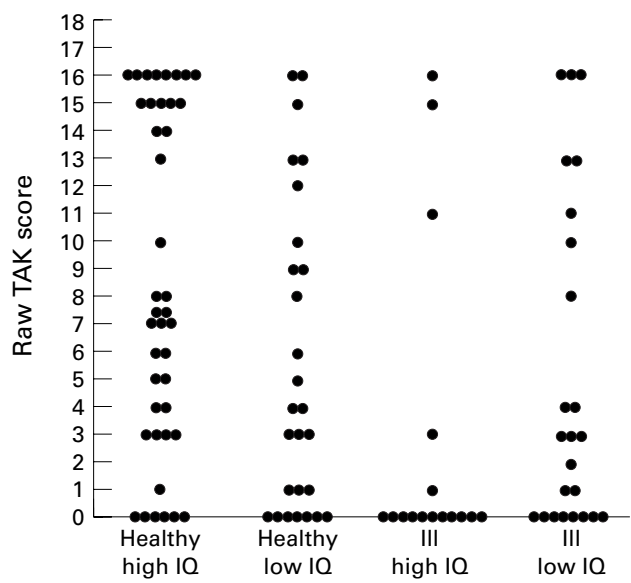

Figure 2 Total anaemia knowledge scores for all subjects.

Results of the analysis of variance indicated that the covariate term-age - was significantly associated with total anaemia knowledge (TAK) scores $(\beta$ 0.68, $\mathrm{t}=10.31, \mathrm{p}<0.001)$ indicating that older children had a better understanding and recall of the story. There was no effect of sex on scores for recall $(\mathrm{f}=0.28, \mathrm{df}=1, \mathrm{p}>0.05)$. There was, however, a significant interaction between experience of illness and IQ $(\mathrm{f}=8.98, \mathrm{df}=1$, $\mathrm{p}=0.003)$. Children with chronic illness and higher IQ had significantly lower TAK scores $(\mathrm{t}=4.21, \mathrm{df}=53, \mathrm{p}<0.001)$ than the control children with higher IQ, although they were well matched in terms of IQ. There was no significant difference between illness groups in the children with lower IQ. The table shows the TAK scores for each group. They have been adjusted for age and $\log$ transformed. Figure 2 shows individual raw TAK scores for each group.

\section{Discussion}

This study found that children with a chronic illness and higher verbal IQ understood and retained significantly less of a simple explanation of an unfamiliar illness than healthy children with similar verbal IQ. This finding will be surprising to many clinicians. However, there is little research evidence to support the commonly held assumption that children with chronic illness will learn new medical information more readily. Most work to date has concentrated on the relation between illness experience and the sophistication of children's illness concepts, and has produced conflicting results. $^{23}$ Few studies have examined the retention of new medical information.

One possible source of error in our study is the lack of a previously validated test to evaluate children's ability to learn new medical information. The tool we have developed, however, appeared to perform as a good test of knowledge. Inter-rater reliability was high and scores correlated with age and, in the control group, with verbal IQ.

There are various possible explanations for our findings. Children with higher verbal IQ may be better able to grasp the implications of their illness and their low scores may reflect an attempt to reduce anxiety by blocking out new information about illness. Alternatively, they may be attempting to disassociate themselves from illness issues. It is possible, however, that they are bored by overexposure to medical information or simply resent the use of the train analogy. To determine whether the effect is specific to analogous explanations we are currently comparing the effectiveness of analogous and non-analogous explanations of medical information.

Children in the study group had either cystic fibrosis or asthma, both of which require adherence to a daily treatment regimen that may include oral or inhaled medication and, in cystic fibrosis, chest physiotherapy. Poor understanding of illness is associated with poor compliance with regular medication. ${ }^{6}$ These results suggest that paediatricians must avoid overestimating their patients' receptiveness to medical information.

1 Charman T, Chandrami S. Childrens understanding of physical illness and psychological states. Psychology and Health 1995;10:145-53.

2 Kury SP, Rodrigue JR. Concepts of illness causality in a pediatric sample: relationship to illness duration, frequency of hospitalisation and degree of life threat. Clin Pediatr 1995;34:178-82

3 Crisp J, Ungerer JA, Goodnow JJ. The impact of experience on children's understanding of illness. F Pediatr Psychol 1996;21:57-72

4 Perrin EC, Perrin JM. Clinicians assessments' of children's understanding of illness. Am f Dis Child 1983;137:874-8.

5 Janovic M, Loiacono NB, Spinetta JJ, Riva LL, Conter V, Masera G. Telling young children with leukemia their diagnosis: the flower garden as analogy. Pediatr Hematol Oncol 1994;11:75-81.

6 Smyth AR, Judd BA. Compliance with antibiotic prophylaxis in urinary tract infection. Arch Dis Child 1993;68:235- 